\title{
Main group elements in unusual coordination environments
}

\author{
Alan H. Cowley \\ Department of Chemistry and Biochemistry, The University of Texas at Austin, \\ Austin, TX 78712
}

\begin{abstract}
By appropriate choice or design of ligands it is possible to place main group elements in low coordination number and/or low oxidation state environments. For example, reactive main group entities such as phosphinidenes and arsenidenes can be stabilized by coordination to carbenes; they can also serve as ligands in $d-$ and $f-$ block metal complexes. Main group fragments can also be incorporated into ring systems and clusters.
\end{abstract}

\section{Introduction}

The overarching theme of this lecture is the chemistry of low coordination number, low oxidation state fragments of the types RE and RM (E = group 15 element; $M=$ group 13 element). Like the familiar carbenes and carbynes, such fragments are, in principle, capable of incorporation into the coordination spheres of $d$ - and f-block metal complexes. Considerable progress has been made recently in the realm of terminal phosphinidene complexes, ${ }^{1}$ which, like the lighter congeneric imido complexes, can exist in angular and linear forms. The first examples of angular ${ }^{2}$ and linear ${ }^{3}$ terminal phosphinidene complexes were reported in 1987 and 1990 , respectively, Since then, it has been demonstrated that the (silox) ${ }_{3}$ Ta fragment (silox $=t-\mathrm{Bu}_{3} \mathrm{SiO}$ ) will support terminal $\mathrm{PPh}$ and $\mathrm{AsPh}$ groups ${ }^{4}$ and the tetradentate triamidoamine ligand $\left[\left(\mathrm{Me}_{3} \mathrm{SiNCH}_{2} \mathrm{CH}_{2}\right)_{3} \mathrm{~N}\right]^{3-}$ has been used ${ }^{5}$ to stabilize a number of linear $\mathrm{Ta}=\mathrm{P}-\mathrm{R}$ moieties. Supplemental Lewis base coordination has also proved to be an effective strategy for the stabilization of terminal phosphinidenes, particularly those involving early transition metals ${ }^{6}$ and f-block elements. ${ }^{7}$

It has been known for several years ${ }^{8}$ that $\mathrm{Me}_{3} \mathrm{P}$ is sufficiently nucleophilic to depolymerize the cyclopolyphosphines $\left(\mathrm{CF}_{3} \mathrm{P}\right)_{4,5}$ and afford the phosphine-phosphinidene complex, $\mathbf{M e}_{3} \mathrm{P} \rightarrow \mathbf{P C F}_{3}$. Very recently, it has become clear that stabilized carbenes are also sufficiently nucleophilic to effect the depolymerization of cyclopolyphosphines and cyclopolyarsines and thus produce carbene-phosphinidene and carbene-arsenidene complexes $1-5,{ }^{9}$ the first examples of $p$-block pnictinidenes.<smiles>[R7]CC1N([R])C([R])=C([R])N1[R]</smiles>

$$
\begin{aligned}
& \text { 1, } R=\mathbf{R}^{\prime}=\mathrm{Me} ; \mathrm{E}=\mathrm{P} ; \mathbf{R}^{\prime \prime}=\mathrm{Ph} ; \mathrm{n}=5 \\
& \text { 2, } R=\text { Mes; } \mathbf{R}^{\prime}=\mathrm{H} ; \mathrm{E}=\mathrm{P} ; \mathrm{R}^{\prime \prime}=\mathrm{Ph} ; \mathrm{n}=5 \\
& \text { 3, } \mathrm{R}=\mathrm{Mes} ; \mathrm{R}^{\prime}=\mathrm{H} ; \mathrm{E}=\mathrm{P} ; \mathrm{R}^{\prime \prime}=\mathrm{CF}_{3} ; \mathrm{n}=4 \\
& \text { 4, } \mathbf{R}=\text { Mes; } \mathbf{R}^{\prime}=\mathrm{H} ; \mathrm{E}=\mathrm{As} ; \mathrm{R}^{\prime \prime}=\mathrm{Ph} ; \mathrm{n}=6 \\
& \text { 5, } R=\text { Mes; } \mathbf{R}^{\prime}=\mathrm{H} ; \mathrm{E}=\mathrm{P} ; \mathbf{R}^{\prime \prime}=\mathrm{C}_{6} \mathrm{~F}_{5} ; \mathbf{n}=4
\end{aligned}
$$


Should the foregoing compounds be regarded as phosphaalkenes and arsaalkenes (i.e. structure 6) or as carbene-pnictinidene complexes (i. e. structure 7)?<smiles>[R][C+](C)C1N([R])C=CN1[R]</smiles>

6<smiles>[R][C-]=C1N([R])C=CN1[R]</smiles>

7

X-ray crystallographic studies on $1-5^{9}$ revealed that the carbon-phosphorus or carbon-arsenic bond lengths are merely $\sim 4 \%$ longer than those of typical single bonds. Moreover, in contrast to the planar phosphaalkenes and arsaalkenes there is a $26-46^{\circ}$ angle of twist between the E-R moieties and the imidazole ring. Further support for the predominance of structure 6 stemmed from the upfield ${ }^{31} \mathrm{P}$ chemical shifts of $1-3$ and the low oxidation potential of $2 .^{10}$ However, since the most conspicuous difference between structures 6 and 7 is the number of phosphorus lone pairs, it was decided to treat 2 with $\mathrm{BH}_{3}-\mathrm{THF}$. The exclusive formation of the bis(borane) adduct 8 is consistent with the carbene-phosphinidene model $6 .{ }^{10}$ The reactivity patterns of carbene-pnictinidenes are currently being studied; however, it has already been<smiles>[R][PH+]=CC1N([R])C=CN1[R]</smiles>

2

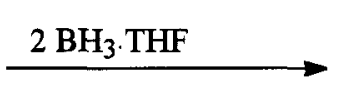<smiles>[R]N1C=CN([R])C1[P+]([R])([B])[Sb]</smiles>

8

established that 2 will react with $\left(\mathrm{CF}_{3} \mathrm{P}\right)_{4}$ to afford 3 and with $\mathrm{BPh}_{3}$ to produce carbene $\mathrm{BPh}_{3}$ and $(\mathrm{PPh})_{\mathrm{n}}(\mathrm{n}$ $=3,4,5$ ), thus suggesting the potential utility of carbene-phosphinidenes as phosphinidene transfer reagents.

Another way to stabilize ER and MR moieties is by incorporation into cyclic structures. The germylene, 1,3-di-tert-butyl-1,3,2-diazagermol-2-ylidene $(9)^{11}$, is proving to be a particularly useful reagent for the introduction of a variety of main group fragments. For example, 9 reacts with group 15 trihalides to afford cyclic phosphenium and arsenium cations $10 a, b .{ }^{12}$ Although the mechanism of this reaction has not been

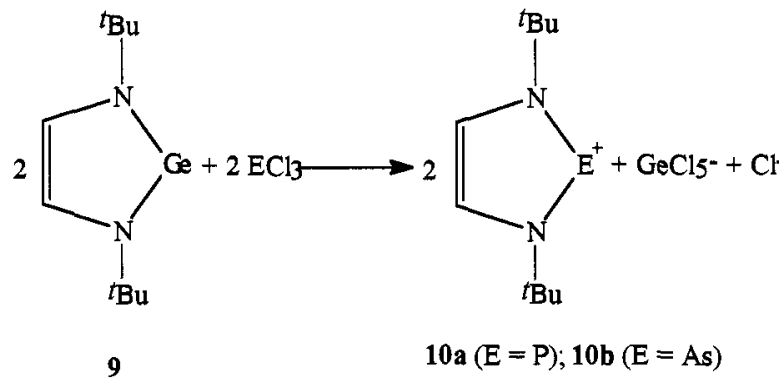

elucidated, it is obvious that a redox process is involved because germanium is oxidized from the +2 to the +4 state. Since it was not clear whether the ionization of the E-Cl bonds was prompted by the presence of the Lewis acid $\mathrm{GeCl}_{4}$ or whether autoionization had taken place, it became important to seek an alternative synthetic approach to these systems. The following metathesis reactions proceed in good yields and an Xray crystal structure analysis of $[10 \mathrm{a}][\mathrm{Cl}]$ revealed that the $\mathrm{P}$. . . Cl separation $(2.715(2) \AA)$ is considerably 


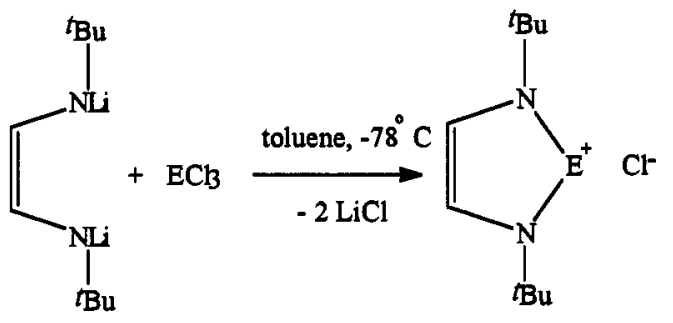

$$
10 \mathrm{a}(\mathrm{E}=\mathrm{P}) ; 10 \mathrm{~b}(\mathrm{E}=\mathrm{As})
$$

shorter than that of typical P(III)-Cl bonds ( 2.1 $\AA$ ), i.e. autoionization has taken place. The saturated analogues $11 \mathrm{a}, \mathrm{b}$ can also be prepared by the metathesis route and, interestingly, the $\mathrm{P}-\mathrm{Cl}$ distance in 11a $(2.425(5) \AA)$ is also longer than that of normal P(III)-Cl bonds, but shorter than that in 10a. There is thus an intriguing parallel with carbene chemistry in the sense that the unsaturated imidazol-2-ylidenes, 12 (Arduengo type) ${ }^{13}$ are more stable as monomers than the C-C saturated analogues, 13 (Wanzlick type). ${ }^{14}$

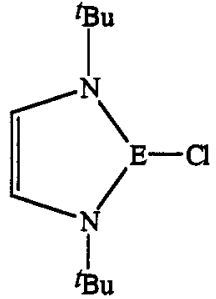

$11 \mathrm{a}(\mathrm{E}=\mathrm{P}) ; 11 \mathrm{~b}(\mathrm{E}=\mathrm{As})$

The electronic structures of stable carbenes (12) have attracted considerable recent attention, the principal questions being whether and to what extent there is electron delocalization in these $6-\pi$ electron systems. ${ }^{15}$ Since group 15 cations (14) and group 13 anions (16) are isoelectronic with the carbenes and heavier congeners (15),<smiles>[R]N1C=CN([R])C1</smiles><smiles>[R]N1CCN([R])C1</smiles>
similar questions arise regarding the possibility of circumannular delocalization.

As pointed out in the case of cyclic nitrenium ions, ${ }^{16}$ the heavier group 15 cations $^{12}$ are expected to exhibit more extensive delocalization than the group 14 analogues (15) because of the existence of a formal positive change at the group 15 center. The $\mathrm{C}-\mathrm{C}$ bond distances in $10 \mathrm{a}(1.330(6) \AA)$ and $10 \mathrm{~b}$

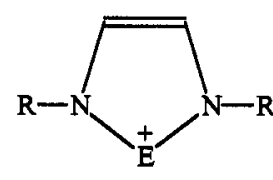

14<smiles>[X]N1[X]N([R])C=C1</smiles>

15<smiles>[R]N1[X]=CN([R])C=C1</smiles>

16

$$
\left(\mathrm{E}=\mathrm{N}^{6}, \mathrm{P}, \mathrm{As}\right) \quad\left(\mathrm{X}=\mathrm{C}^{2}, \mathrm{Si}^{17}, \mathrm{Gel}^{11}\right) \quad(\mathrm{X}=\mathrm{B}, \mathrm{Al}, \mathrm{Ga})
$$
$(1.36(2) \AA)$ are very similar to those in the isoelectronic silylene $(1.347(2) \AA)^{17}$ and germylene $(1.36(1) \AA)^{11}$ and correspond to localized double bonds. Moreover, the P-N bond distance in 10a (1.651(4) $\AA$ ) is longer than that in the acyclic phosphenium cation $\left[\left(i-\mathrm{Pr}_{2} \mathrm{~N}\right)_{2} \mathrm{P}\right]^{+}$(av. $\left.1.613(4) \AA\right)^{18}$ and, interestingly, the P-N and As- $\mathrm{N}$ bond distances in 10a,b are longer than those in the analogous saturated cations 11a,b. Overall, therefore, the metrical parameters for the cations provide little support for extensive delocalization. It will, of course, be interesting to prepare and structurally characterize a group 13 anionic species (16). So far, we have prepared a gallium-gallium bonded derivative (17) by the metathetical route shown below. ${ }^{19}$ Efforts are underway to isolate the anion resulting from two-electron reduction of 17.

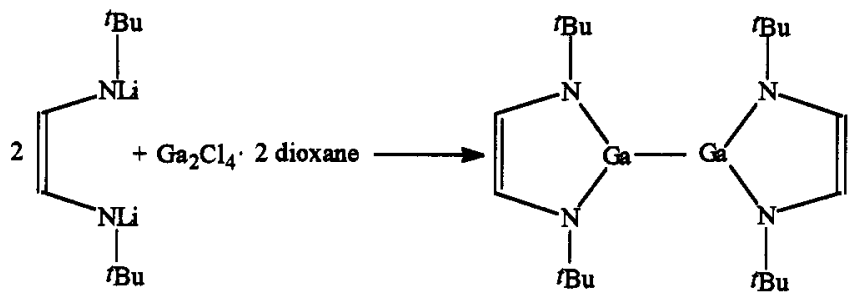




\section{Acknowledgement}

It is a pleasure to acknowledge the outstanding contributions of the graduate students, postdoctoral associates, and collaborators whose names appear in the references. Thanks are also due to the National Science Foundation and the Robert A. Welch Foundation for financial support.

\section{$\underline{\text { References }}$}

1. For a review, see A. H. Cowley, Acc. Chem. Res. 1977, in press.

2. P. B. Hitchcock, M. F. Lappert, W.-P. Leung, J. Chem. Soc., Chem. Couumn. 1282 (1987); P. Bohra, P. B. Hitchcock, M. F. Lappert, W.-P. Leung Polyhedron 8, 1184 (1989).

3. A. H. Cowley, B. Pellerin, J. L. Atwood, S. G. Bott, J. Am. Chem. Soc. 112, 6734 (1990).

4. J. B. Bonanno, P. T. Wolczanski, E. B. Lobkovsky, J. Am. Chem. Soc. 116, 11159 (1994); P. T. Wolczanski, Polyhedron 14, 3335 (1995).

5. C. C. Cummins, R R. Schrock, W. M. Davis, Angew. Chem., Int. Ed. Engl. 32, 756 (1993); R. R. Schrock, Acc. Chem. Res. 30, 9 (1997).

6. See, for example, Z. Hou, T. L. Breen, D. W. Stephan, Organometallics 12, 3158 (1993).

7. D. S. J. Arney, R C. Schnabel, B. C. Scott, C. J. Burns, J. Am. Chem. Soc. 118, 6780 (1996).

8. A. B. Burg, W. Mahler, J. Am. Chem. Soc. 83, 2388 (1961).

9. A. J. Arduengo, III, H. V. Rasika Dias, J. C. Calabrese, Chem. Lett. 143 (1997); A. J. Arduengo, III, J. C. Calabrese, A. H. Cowley, H. V. Rasika Dias, J. R. Goerlich, W. J. Marshall, B. Riegel, Inorg. Chem 36, 2151 (1997).

10.A. J. Arduengo, III, C. J. Carmalt, J. C. Clyburne, A. H. Cowley, R. Pyati, Chem. Comm. 981 (1997).

11.W. A. Herrmann, M. Denk, J. Behm. W. Scherer, F.-R. Klingan, H. Bock, M. Soluki, M. Wagner, Angew. Chem., Int. Ed. Engl 31, 1485 (1992).

12.C. J. Carmalt, V. Lomeli, B. G. McBurnett, A. H. Cowley, Chem. Comm. In Press.

13.A. J. Arduengo, III, R. L. Harlow, M. Kline, J. Am. Chem. Soc. 113, 361 (1991); A. J. Arduengo, III, H. V. Rasika Dias, R. L. Harlow, M. Kline, J. Am. Chem. Soc. 114, 5530 (1992).

14.H.-W. Wanzlick, E. Schikora, Angew. Chem. 72, 494 (1960); H.-W. Wanzlick, Angew. Chem. 74, 129 (1962).

15.See, for example, C. Heinemann, T. Müller, Y. Apeloig, H. Schwarz, J. Am. Chem. Soc. 118, 2023 (1996); C. Boehme, G. Frenking, J. Am. Chem. Soc. 118, 2039 (1996).

16.G. Boche, P. Andrews, K. Harms, M. Marsch, K. S. Rangappa, M. Schimeczek, C. Willeke, J. Am. Chem. Soc. 188, 4925 (1996).

17.M. Denk, R. Lennon, R. Hayashi, R. West, A. V. Belyakov, H. P. Verne, A. Haaland, M. Wagner, N. Metzler, J. Am. Chem. Soc. 116, 2691 (1994).

18.A. H. Cowley, M. C. Cushner, J. S. Szobota, J Am. Chem. Soc. 100, 7784 (1978).

19.D. S. Brown, A. Decken, A. H. Cowley, J. Am. Chem. Soc. 117, 5421 (1995). 